\title{
THE MEANING OF SILENCE IN PERSONAL COMMUNICATION: SPIRAL OF SILENCE OR A STIMULANT OF CREATIVITY?
}

\author{
Radoslav Velimir BALTEZAREVIĆ (D) ${ }^{1^{*}}$ Piotr Benon KWIATEK (D) ${ }^{2,3}$, \\ Borivoje Velimir BALTEZAREVIĆ (D) ${ }^{4}$, Vesna Nikola BALTEZAREVIĆ (D) ${ }^{5}$ \\ ${ }^{1}$ Marketing Department, Faculty of Business Studies, Megatrend University, \\ Bulevar maršala Tolbuhina 8, 11070 Belgrade, Republic of Serbia \\ ${ }^{2}$ Marketing Department, Kozminski University, 57/59 Jagiellonska Street, 03-301 Warsaw, Poland \\ ${ }^{3}$ Global Sales and Marketing Department, Faculty for Business \& Management, University of Applied \\ Sciences Upper Austria, Wehrgrabengasse 1-3, 4400 Steyr, Austria \\ ${ }^{4}$ Department for Media Management, Faculty of Management, Union-Nikola Tesla University, \\ Njegoševa St. 1a, 21205 Sremski Karlovci, Republic of Serbia \\ ${ }^{5}$ Department of Law and Security, Faculty of Law, Megatrend University, \\ Bulevar maršala Tolbuhina 8, 11070 Belgrade, Republic of Serbia
}

Received 19 October 2019; accepted 6 April 2021

\begin{abstract}
Silence is an important part of communication. Depending on the cultural context, silence can be perceived as positive/desirable or as negative/unwelcome. This ambiguity often leads to misunderstandings with other participants in the communication process. The current study discusses the phenomenon of silence and presents the spiral of communication, as a part of nonverbal communication, and refer to the synthesis of silence and creativity. We approach important questions in our study: is silence in communication linked with creativity. If so, through what mechanism? Does the tension in communication affect silence being used as a mode of escaping from a communication process to avoid conflict, tension and uncomfortable situations? Based on the analysis of the theoretical approaches to these phenomena, we empirically test ordinary least squares mediation models based on responses collected from 416 individuals of Serbian nationality. Our study reveals that silence is used to avoid conflict in communication by reducing the feeling of tension. We note that silence does not affect creativity directly. Rather, it has a marginal effect through reducing tension and avoiding conflict and while having opposite opinions.
\end{abstract}

Keywords: communication, creativity, cultural context, isolation, nonverbal communication, silence, spiral of silence.

\section{Introduction}

Conversational silence - an act of saying nothing when words are expected - is used by people when they communicate with each other on a daily basis. When silence is used, a conversation partner tries to decipher the meaning based on the culture, context and situation

*Corresponding author. E-mails: rbaltezarevic@megatrend.edu.rs; radoslav@ciim.ac.cy; rbaltezarevic@gmail.com

Copyright (C) 2022 The Author(s). Published by Vilnius Gediminas Technical University

This is an Open Access article distributed under the terms of the Creative Commons Attribution License (http://creativecommons. $\mathrm{org} / \mathrm{licenses} / \mathrm{by} / 4.0 /$ ), which permits unrestricted use, distribution, and reproduction in any medium, provided the original author and source are credited. 
of its use. Understanding of differences in communication patterns among people and cultures can help in avoiding unwanted communication obstacles. The meaning of silence is different in various situations. One of the main needs for communicators is to be aware of the degree of tolerance of silence. How to understand someone during a conversation more correctly and to escape from the unpleasant feeling of misunderstanding? It is doable by enhancing interpersonal and intercultural communication by studying of the silence meanings and communication functions in different cultures. What are the bright and dark sides of silence in communication, and what are the advantages and disadvantages of using silence in everyday conversations, are questions needed to be decoded? Since Noelle-Neumann introduced a spiral of silence theory (1974) based on the claim that people are silent when faced with the fear of social isolation, the other researchers have mostly accepted her opinion without testing it (Taylor, 1982, p. 314). Silence is not only used in a situation where communicators face the fear of social isolation, as communicators can keep silent because of willingness to create interpersonal distance (Richmond \& McCroskey, 1999, pp. 323-324) when they are faced with the different modus of dialectical tension. People used silence in the occasion when they are faced with an uncertain flow of communication such as "uncertainty, unpredictability, or ambiguity" (Braithwaite, 2009), or when they fill the discomfort among unfamiliar persons (Tannen \& Saville-Troike, 1985) which leads to tension. Silence may be understood as an incubator for creativity. According to LeClaire,

"like the solitary spider who busily weaves her web in perfect silence, we need to be alone and quiet for our subconscious to spin its creations. Picasso said solitude is necessary for creative work, 'In silence's calm surrounds, we discover the power of imagination and throw open the gates to creativity'. In the opulent luxury of solitude, time becomes elastic and creative impulses surface and are allowed room to breathe" (2010, pp. 136-137).

The goals set in this paper are related to the analysis of the research questions:

1. Are people whose opinion is different from the majority of the mind keeping silent because they feared social isolation?;

2. Does the tension in communication affect silence being used as modus for escaping from a communication process to avoid conflict, tension and uncomfortable situations?

The paper is structured as follows. First, relevant theories about the use of silence in daily communication and the assumptions for its understanding are considered. The second part presents the results of the research on attitudes. In specific, spiral of silence is evaluated along with various emotional motives, which authors defined as tension in communication.

\section{Silence as nonverbal communication}

“Do we talk only when we are speaking?” (Jaworski, 1993, p. 25).

Montgomery and Baxter (2008) first pointed out to dialectic tensions as a prominent communicative phenomenon. Tension often occurs during human interaction. Silence is influenced by "interpersonal or group tension" (Prentice \& Kramer, 2006, p. 358) and can be seen as "elimination of interpersonal psychic tensions" (Baker, 1955, p. 161). The tension that occurs during communication, according to Montgomery (1993) can never be eliminated. Silent 
mode is also used in a possible conflict situation as a conflict management tactic (Saunders, 1985, p. 165; Tannen, 1990), when silence "is a substitute for direct expression of negative emotion to manage conflict" (Tannen, 1990, p. 276), while conflict is described as "behavior that negatively impacts another individual or group" (Starks, 2006).

"Silence is a medium of communication whose processing requires more cognitive effort than speech" (Jaworski, 1993, p. 141) as

"man is involved in language even when he is silent. Silence is more than unspoken language. Words are present in the silence; they are an organic part of the human face and form" (Picard, 1963, p. 46).

Silence can have diverse meaning in the communication process. It can be understood as a time to think, consider a response or to express emotions. Basil of Caesarea (330-379) argued: "The good of silence is dependent on the time and the person, as we are taught by the God-inspired Scripture" (Silvas, 2005, p. 387). For a long time, it was believed that silence only had a function of creating boundaries (prosodic function) and was defined as an absence of speech or as "periods of non-speech or non-vocalization in conversation" (Zuo, 2002, p. 4; Tannen \& Saville-Troike, 1985). However, silence is also used as a communicative response (Tatar, 2005).

Undoubtedly, the use of silence in communication is culture-bounded (Carbaugh, 2010). In the United States (US), for example, people are not very comfortable with silence, it is often used to represent disapproval, or it is just a time to rearrange thoughts in order to prevent saying something they might later regret. Since US is considered a low-context country, people have a tendency to fill the silence gaps in communication with comments on the weather or some other general topics to avoid unpleasant feelings caused by silence. Silence has suffered a negative image. It is often viewed badly as the lack of language, while speech is understood as the "characterizing signature of humanity" (Kane, 1984, p. 13).

In some other cultures, silence is considered an integral part of communication, a good example are countries in Asia and Scandinavia. In Scandinavia, the silence is not understood as mere quietness, but a way of life and being close to nature. For the Japanese, silence presents nothingness, or a metaphysical way of inner connection, as explored through Buddhism (Broner-Bauer, 1998). In Japan, a high-context culture, the person who doesn 't use periods of silence during conversation is considered as someone who is not thinking a lot about what he/she is saying, and that person is out of focus. For the Japanese the use of silence can be a way of showing respect for what has been said, after the speech for example, as "the most profound statements are often said in silence" (Shafik, 2011, p. 451). This effectively corrects the notion that multitude of words must precede making sense. Nowadays society is in close connection and it is important to recognize and be aware of different cultures when trying to understand and define the qualities of silence. In not-so-distant China, silence is praised and encouraged. Publilius Syrus stated "I have often regretted my speech, but never my silence" (Umeh, 2010, p. 4).

Silence, as we see, is used in many different forms in different cultures that are why we need to think about what is being communicated to us via the silence. We need to remember that silence can be also positive. The person we communicate with is maybe just confused or is trying to show respect. In many cases, they are only thinking about what has been said in earlier conversation and want to truly understand the other person's comments. 
Courtenay (1916) proposed the term silence as ignorance, or ignorant silence, that appears in situations when people simply were not aware of something. He said that ignorance does not have to be bad, because people may simply lack the ability or tools to perceive certain situations or things, and sometimes are just consequently incapable of communicating. However, as he said, for him was very negative were people who keep themselves intentionally ignorant of a thing:

"It is generally agreed among communication scholars that whether a man talks or refuses to talk, he is communicating some message to those expectant communicants who are in some form of interaction with him" (Wilson, 2005, p. 42).

We can say that even not saying anything is saying a lot.

During our lives, we are often in situations where people from our environment are not saying anything, but it does not mean that they have not communicated. Actually, they have, but their silence is, in that case, intentional and strategic. Wilson defined strategic silence as "the deliberate use of silence to communicate certain feelings, like anger, distancing, rejection, etc., in order to achieve a set of personal objectives" (2005, p. 43).

We can conclude that silence is strategic when a person decides to maintain quietness in order to gain some results or to prove a point to the other person.

\section{Positive and negative aspects of silence}

Silence and its symbolic nature can be understood differently. The best example may be a woman's silence after a marriage proposal. The same silent reaction may be interpreted as acceptance or rejection in some other occasions and cultural settings (Nakane, 2007). As one of the positive aspects of silence, Nakane (2007) found that silence benefit both speaker and listener: Without silence, listeners have great difficulty in keeping up with ongoing talk and interpreting it correctly. Silence belongs to language and it is positive (Picard, 1963, p. 32) and very often it can be used as a sign of politeness and prevent disagreement (Padilla Cruz, 2008) and conflict as "it is easier to undo silence than it is to undo words" (Jaworski, 1993, p. 25). We should mention the negative side of silence as well. Silence enhanced with meaning is known as "attributable silence" (Cutting, 2008, p. 29), and in cultures with a low tolerance for silence, long silences during conversation may cause discomfort. In Western countries, silence is usually disturbed after a very short period of time, the reason for that is a feeling of tension, created by the long pauses that people want to escape (Gould, 2008).

Duff (2002) reported that non - native speaking students are often afraid of being criticized and to feel discomfort because of their bad English skills, so they use silence in order to protect themselves. Similarly, Nakane (2007) point out that silence is often wrongly seen as a lack of adherence or a negative attitude towards studies. Because of that, the Non - Native speaking students are often in the middle of two unfriendly options: mockery or hostility.

\subsection{Spiral of silence}

Noelle-Neumann developed the theory of spiral of silence in 1974, arguing that if members of a group assume most of the group shares the same thoughts and views, then whether or 
not each person actually believes it, the perception and beliefs of the majority are enough to silence dissenting views over time (Glynn et al., 1997, p. 452). People have a tendency to use a "quasi-statistical sense" to define and measure if their opinions are popular or unpopular (Hayes, 2007, p. 785). If they figure out that they share their opinions with the majority of the group, they may be willing to speak out. But, if they realize their opinions are the opposite, they will keep silent or comply with the view of the majority. The reason one view was able to silence other views was that people feared isolation more than being wrong (Liu \& Fahmy, 2011, p. 46). In short, social sanctions play a key role, and Noelle-Neumann theory (1974) suggests that silence is a state in which members who hold minority viewpoints believe they cannot express themselves because of the fear of isolation from their larger community (Moy et al., 2001), as "man is a social being with a potent desire to belong, both at the individual and larger social group levels" (V. Baltezarevic \& R. Baltezarevic, 2016b, p. 194).

However, fear of isolation may not be the only cause for such reactions, but the root of that fear may be linked to survival and uncontrollable instinct, as biologists discovered, people have evolved to recognize that personal survival is tightly connected to group survival (Sloan Wilson \& Wilson, 2007). We can conclude, also, that the local culture perceives dissenting viewpoints as threatening and would use social isolation as a controlling tool, whereas a culture that desired dissenting views would not choose that option. Unfortunately, many types of research that have studied the spiral of silence continue to provide proof that most cultures still do perceive dissent as anti-social (Simpson, 1996).

On the other hand,

"when people believe that they share the same opinions or if their options are becoming more popular, they express themselves openly, outside their circle of family and friends" (Jeffres et al., 1999, p. 115).

The spiral of silence theory has usually been used by scholars of political communication and has been studied to test the willingness of individuals to speak out about controversial topics of society (Liu \& Fahmy, 2011, p. 45).

Noelle-Neumann theory (1974) also has been criticized and discussed whether fear of isolation has enough power to discourage speaking out or to express disagreement with the majority (Scheufle \& Moy, 2000).

\subsection{Silence and creativity: a synthesis}

Creativity is defined as "the production of novel, appropriate ideas in any realm of human activity, from science, to the arts, to education, to business, to everyday life" (Amabile, 1997, p. 40). It is considered one of the most complex human behaviors. Creativity can be influenced by a wide range of social, educational and developmental experiences that lead to creativity in different ways in different areas (Runco \& Okuda Sakamoto, 2002). Guilford defined creativity as "the abilities that are most characteristic of creative people" (1950, p. 444). According to Cook (2002) creativity can be define as the following: a divine quality, planned luck, serendipitous activity, endurance and method. Dewett (2004) defines creativity as "the production of novel and useful ideas, processes, or products by a person or group". Creativity is usually considered as the production of new and useful ideas or solutions to prob- 
lems (Woerkum et al., 2007). It can be said that originality, flexibility, breaking boundaries, independence and unconventionality are universal criteria that represent creativity (Ulger, 2020). Many authors in this field have stated that challenging, innovation, and broadening are important features to predict creativity (Runco, 2017):

"Jung wrote that creativity is an instinct, not an optional gift granted to a lucky few. If you don't find a way to be creative in life, that instinct goes repressed and frustrated. You feel its loss as a deflation, the spirit leaking out of your sense of self. You feel empty, disengaged, and unfulfilled" (Moore, 2008, p. 2).

Creativity is considered as an important quality of successful leaders, a quality that represents the ability to introduce new and convincing ideas (Mayer \& Maree, 2018). From the moral point of view, creativity presupposes credibility due to the need to shape a person to be educated and developed in and by the society, in which he/she lives, until that person become a creative entity, able to use his or her creativity in cooperation with other entities (Mazur \& Duchlinski, 2020).

The literature review is suggesting two contrasting predictions, first one is that thinking aloud may lead to more creative ideas than thinking in silence, and the second, thinking aloud may lead to less creative ideas, than thinking in silence. Indirect evidence can be found in the literature for both predictions. Regarding the first prediction, it is theoretically grounded in language and cognitive psychology and relates with work on object design (Wetzstein \& Hacker, 2004). The second prediction is consistent with studies on group brainstorming (Mullen et al., 1991) and with work on insight problems (Kim, 2002). Levelt (1993) argues there is a good reason to believe thinking aloud may actually hinder creative thought. $\mathrm{He}$ adds that speech production, and actually articulating - requires cognitive processing. Therefore, thinking aloud may decrease the processing capacity available for creative performance. Ritchie Key argues, that "the comforting, companionable silence between people in equilibrium [...] must be distinguished from the negative, disturbing silence of anger, fear, or hate" (1975, p. 128):

"Silence creates a rare opportunity to pause and drop into stillness, to become intimate with your own mind. When we start the journey to attune to our own minds by pausing into stillness, we enter a new realm of experience that can produce surprise in each moment [...]. As the stillness permits the mind to 'settle', it becomes possible to be aware of the subtleties in the fine structure of the mind's functions. Stillness is not the same as a void in activity, it's more like a stabilizing strength" (Siegel, 2007, pp. 61-73).

The natural silence or periods when creative life lies at a standstill, and unnatural silences, imposed on people by the acquisition of circumstances such as class, educational disadvantage, race, sex, or the demands of nurturing. Cleveland Morris said, "I don't think art is possible without silence. The ultimate spiritual discovery is in silence, not in noise" (LeClaire, 2010, pp. 113-133). Sarton stated,

"Each time I come back here the same miracle happens. I bring the world with me, but at a certain moment the world falls away and I am inside the life-restoring silence" (1999). 
Based on the available literature analysed in this paper, we have set the following hypotheses:

H1. People with the opinions opposite of the group will keep quiet because they are afraid of social isolation;

$\mathrm{H} 2$. When a communicator fills a tension, silence is a mode of escaping from a communication process to avoid conflict, tension and uncomfortable situations.

\section{Methodology and results: data collection}

The questionnaire for this research was composed of two parts. The first part of the questionnaire consisted of questions related to respondents' attitudes on the reasons for using silence in the communication process.

Questions in the second part pertained to the demographic profile of the respondents (gender, age and level of education). A screening question was used to single out the respondents who are consciously using silence in communication. Respondents' attitudes were measured using 5-point Likert-type scales, anchored from 5 = "strongly agree" to $1=$ "strongly disagree".

According national statistics, Serbian population aged 18 to 65 years tops to 4436507 (Republika Srbija: Republički zavod za statistiku, 2020), thus the minimum sample size for $95 \%$ confidence level and 5\% confidence interval is 384 respondents.

Data was collected from mid-December 2018 to beginning of February 2019. The invitation to take part in the research was sent to $592 \mathrm{e}$-mail addresses available in the university panel data in the territory of Serbia. Participants were offered a free research report for taking part in the survey. Within two weeks, 387 questionnaires were received (65.4\%) and a reminder was sent to all addresses. This resulted in an additional 36 questionnaires received (423 in total). For further analysis, 416 properly filled questionnaires were used (70.3\%). To ensure that the dataset is not prone to non-response bias, early and late respondents were compared (Anderson, 1979).

\section{Basic descriptives}

Table 1 shows a basic description of the sample. The participants of the survey were mainly below 35 years of age (56\%), with higher education (64.7\%). Women represented more than half of the sample (53.1\%), a fair comparison with 2011 census data (51.3\%) (Republika Srbija: Republički zavod za statistiku, 2020).

The constructs' means, standard deviations and correlations are presented in Table 2.

The linearity and monotonicity assumptions were verified through the analysis of scatterplot for all variables in the study (Figure 1).

More in-depth correlation analysis provided insights into possible relationships between constructs. People with the opinions opposite to the group keep silent because they feared social isolation $c^{2}(16,416)=858.79, p<.01$, rho $=.914, p<.01$. The association is positive and significant $(\mathrm{G}=.957, p<.01)$. As gamma is a proportional reduction of error type of measure, it can be concluded that knowing the level towards the claim that people with the 
Table 1. Demographic profile of respondents $(\mathrm{N}=416)$ (source: created by authors)

\begin{tabular}{|c|c|c|}
\hline Demographic & $\mathrm{n}$ & $\%$ \\
\hline \multicolumn{3}{|c|}{ Gender } \\
\hline Male & 195 & 46.9 \\
\hline Female & 221 & 53.1 \\
\hline \multicolumn{3}{|c|}{ Age } \\
\hline Less than 25 & 113 & 27.2 \\
\hline $26-35$ & 120 & 28.8 \\
\hline $36-45$ & 124 & 29.8 \\
\hline $46-55$ & 39 & 9.4 \\
\hline $56-65$ & 20 & 4.8 \\
\hline \multicolumn{3}{|c|}{ Education } \\
\hline High school & 111 & 26.7 \\
\hline College & 119 & 28.6 \\
\hline University & 150 & 36.1 \\
\hline $\mathrm{MBA}^{\star} / \mathrm{PhD}^{\star *}$ & 36 & 8.7 \\
\hline
\end{tabular}

Note: ${ }^{\star} \mathrm{MBA}-$ Master of Business Administration; ${ }^{\star *} \mathrm{PhD}-$ Doctor of Philosophy.

Table 2. Mean, standard deviation, and correlations (source: created by authors)

\begin{tabular}{|c|c|c|c|c|c|c|c|c|}
\hline Construct & 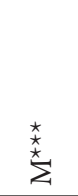 & 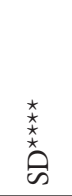 & 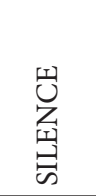 & 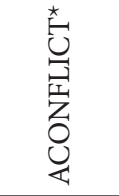 & 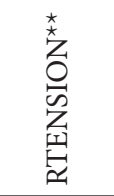 & 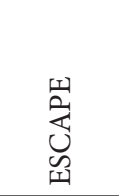 & 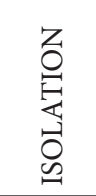 & 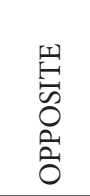 \\
\hline SILENCE & 2.98 & 0.82 & 1.00 & & & & & \\
\hline ACONFLICT $^{*}$ & 2.72 & 1.04 & .002 & 1.00 & & & & \\
\hline RTENSION $^{\star *}$ & 2.58 & 0.87 & $.116^{(1)}$ & $-.217^{(1)}$ & 1.00 & & & \\
\hline ESCAPE & 3.19 & 0.99 & .031 & $.225^{(1)}$ & $-.739^{(1)}$ & 1.00 & & \\
\hline ISOLATION & 2.81 & 0.97 & -.031 & $-.185^{(1)}$ & $.849^{(1)}$ & $-.741^{(1)}$ & 1.00 & \\
\hline OPPOSITE & 2.46 & 0.88 & -.013 & $-.093^{(2)}$ & $.448^{(1)}$ & $-.613^{(1)}$ & $.598^{(1)}$ & 1.00 \\
\hline CREATIVITY & 2.58 & 1.00 & -.018 & $-.098^{(2)}$ & $.421^{(1)}$ & $-.559^{(1)}$ & $.559^{(1)}$ & $.741^{(1)}$ \\
\hline
\end{tabular}

Note: ${ }^{\star}$ ACONFLICT - conflict avoidance; ${ }^{\star *}$ RTENSION - reducing tension; ${ }^{\star * *} \mathrm{M}=$ mean; ${ }^{* * *} \mathrm{SD}=$ standard deviation; ${ }^{(1)}$ significant at $p<0.01 ;{ }^{(2)}$ significant at $p<0.05$. 


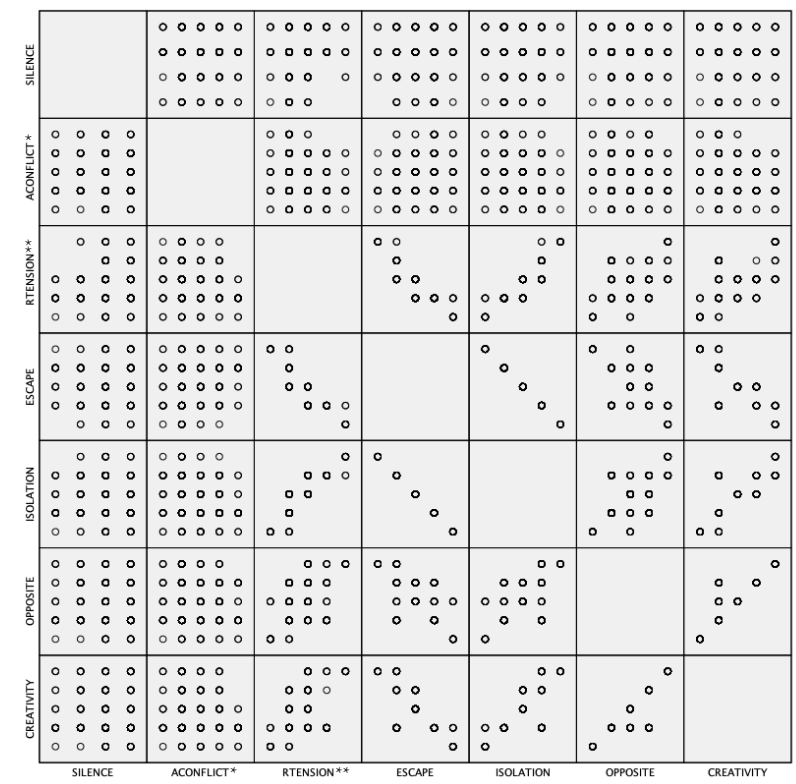

Note: ${ }^{\star}$ ACONFLICT - conflict avoidance; ${ }^{*}$ RTENSION - reducing tension.

Figure 1. Scatterplot for constructs (source: created by authors)

opinions opposite of the group will keep silent improves the prediction of people being silent because of fear of social isolation by $95.7 \%$. When a communicator experiences tension, she uses silence to avoid conflict $c^{2}(16,416)=46.283, p<.01$, rho $=.259, p<.01$. The strength of the relationship between those variables was tested by gamma measure of association. The association is positive and moderate $(\mathrm{G}=.320, p<.01)$ so it can be concluded that a feeling of tension improves the prediction of using silence to avoid conflict by $32.0 \%$.

Further, Somers' D was evaluated to determine the association between the use of silence and the use of silence to reduce tension. There was a weak, positive correlation between the use of silence and treating silence as means to reduce tension, which was statistically significant $(\mathrm{D}=.12, p<.01)$. There is no association between the use of silence and avoiding the conflict $(\mathrm{D}=.02, p>.05)$.

We find no correlation between creativity and the use of silence in order to avoid conflict $\left(\chi^{2}(16,416)=22.871, p>.01\right)$. However, creativity is associated with keeping silent because of having opposite opinions $\left(\chi^{2}(16,416)=1296.844, p<.01\right)$ and reducing the tension $\left(\chi^{2}(16,416)=541.649, p<.01\right)$. Both associations show strong relationship. Using silence while having opposing views increases creativity by $87 \%(\mathrm{G}=.87, p<.01)$ and using silence to reduce the tension increases creativity by $59 \%(\mathrm{G}=.59, p<.01)$.

These findings are in line with suggestions derived from prior studies. While Byron et al. (2010) note that stress decreases creativity, Guo et al. (2018) pose that in face of workplace fear defensive silence inhibits creativity. It is however important to note that Guo et al. (2018) explicitly discuss authoritarian leadership and workplace environment, while our study concentrates on casual communication. 


\section{Hypotheses testing}

To test the hypothesized relationships, we used PROCESS macro 3.0 (Hayes, 2007) in SPSS Statistics 23.0. The parallel multiple mediator models for ordinary least squares was formulated as follows:

$$
\begin{gathered}
Y=i_{y}+c^{\prime} X+b_{1} M_{1}+b_{2} M_{2}+e_{y} \\
M_{1}=i_{M 1}+a_{1} X+e_{M 1} ; \\
M_{2}=i_{M 2}+a_{2} X+e_{M 2} .
\end{gathered}
$$

The dependent variable (Y) depicts the conflict avoidance (ACONFLICT). The use of silence (X = SILENCE) affects ACONFLICT directly and through two mediators: reducing tension $(\mathrm{M} 1=\mathrm{RTENSION})$ and having opposite opinions to the group (M2 = OPPOSITE).

The confidence intervals for coefficient estimates and the effects (both direct and indirect) were bootstrapped using 5000 samples. The resulting model exhibits acceptable accuracy $(F$ $\left.(3,412)=8.2086, p<0.01, R^{2}=.24\right)$.

Table 3. Coefficient estimates for ordinary least squares model (source: created by authors)

\begin{tabular}{|l|c|c|c|c|c|}
\hline \multicolumn{1}{|c|}{ Construct } & $\mathrm{B}^{* * *}$ & $\mathrm{t}$-value & SE $^{* * * *}$ & LLCI $^{* *}$ & ULCI $^{* * * * *}$ \\
\hline SILENCE & .0369 & .5987 & .0617 & -.0843 & .1582 \\
\hline RTENSION & -.2851 & 4.1571 & .0686 & -.4199 & -.1503 \\
\hline OPPOSITE & .0003 & .0040 & .0677 & -.1328 & .1334 \\
\hline
\end{tabular}

Note: ${ }^{*} \mathrm{RTENSION}-$ reducing tension; ${ }^{* *} \mathrm{LLCI}=$ lower bound of $95 \%$ confidence interval; ${ }^{* * *} \mathrm{~B}=$ unstandardized coefficient; ${ }^{* * *} \mathrm{SE}=$ standard error of coefficient; ${ }^{* * * *} \mathrm{ULCI}=$ upper bound of $95 \%$ confidence interval; constant was omitted.

Results provided in Table 3 show that silence is used to avoid conflict in communication only through reducing the feeling of tension. The total indirect effect is small $(c=-.047)$.

$$
\begin{aligned}
\text { ACONFLICT } & =3.35-0.29 * \text { RTENSION }+1.02 ; \\
\text { RTENSION } & =2.09+0.17 * \text { SILENCE }+0.77 .
\end{aligned}
$$

The serial-parallel multiple mediator models for ordinary least squares is formulated as follows:

$$
\begin{gathered}
Y=i_{y}+c^{\prime} X+b_{1} M_{1}+b_{2} M_{2}+b_{3} M_{3} e_{y} \\
M_{1}=i_{M 1}+a_{1} X+e_{M 1} \\
M_{2}=i_{M 2}+a_{2} X+d_{21} M_{1}+e_{M 2} \\
M_{3}=i_{M 3}+a_{3} X+e_{M 3} .
\end{gathered}
$$

The dependent variable (Y) depicts the creativity (CREATIVITY). The use of silence (X = SILENCE) affects CREATIVITY directly, through two serial mediators: (M1 = RTENSION and M2 = ACONFLICT) and one parallel mediator (M3 = OPPOSITE).

The confidence intervals for coefficient estimates and the effects (both direct and indirect) were bootstrapped using 5000 samples. The resulting model exhibits acceptable accuracy $(F$ $\left.(3,412)=272.31, p<0.01, R^{2}=.67\right)$. 
Table 4. Coefficient estimates for ordinary least squares model (source: created by authors)

\begin{tabular}{|l|c|c|c|c|c|}
\hline \multicolumn{1}{|c|}{ Construct } & $\mathrm{B}^{* *}$ & $t$-value & $\mathrm{SE}^{* * *}$ & LLCI****$^{*}$ & ULCI****$^{* *}$ \\
\hline SILENCE & -.0400 & 1.1409 & .1547 & -.1089 & .0289 \\
\hline ACONFLICT & -.0950 & 3.4323 & .0686 & -.1495 & -.0406 \\
\hline OPPOSITE & .7675 & 28.1520 & .0273 & .7139 & .8211 \\
\hline
\end{tabular}

Note: ${ }^{*} \mathrm{ACONFLICT}$ - conflict avoidance; ${ }^{* *} \mathrm{~B}=$ unstandardized coefficient; ${ }^{* *} \mathrm{SE}=$ standard error of coefficient; ${ }^{\star * * *}$ LLCI $=$ lower bound of $95 \%$ confidence interval; ${ }^{\star * * * *}$ ULCI $=$ upper bound of $95 \%$ confidence interval; constant was omitted.

Table 5. The indirect effects (source: created by authors)

\begin{tabular}{|c|c|c|c|c|}
\hline The path & $\mathrm{f}^{* * *}$ & $\mathrm{SE}^{\star * * *}$ & $\operatorname{LLCI}^{* * * * *}$ & $\mathrm{ULCI}^{\star * * * * *}$ \\
\hline M1: SILENCE -> OPPOSITE -> CREATIVITY & .0096 & .0512 & .0924 & .1074 \\
\hline $\begin{array}{l}\text { M2: SILENCE }->\text { RTENSION }^{* *}->\text { ACONFLICT }^{*}-> \\
\text { CREATIVITY }\end{array}$ & .0044 & .0021 & .0011 & .0096 \\
\hline
\end{tabular}

Note: ${ }^{*}$ ACONFLICT - conflict avoidance; ${ }^{* *}$ RTENSION - reducing tension; ${ }^{* * *} \mathrm{f}=$ effect size; ${ }^{* * *}$ SE $=$ standard error of estimation; ${ }^{\star * * * *}$ LLCI $=$ lower bound of $95 \%$ confidence interval; ${ }^{\star * * * \star}$ ULCI $=$ upper bound of $95 \%$ confidence interval; constant was omitted.

The results provided in Tables 4 and 5 indicate that silence does not affect creativity directly. Rather, it has a marginal effect through reducing tension and avoiding conflict $\left(f_{1}=\right.$ $.004)$ and while having opposite opinions $\left(f_{2}=.01\right)$. It is important to note, that the use of silence while having different opinion can have a stronger effect on creativity than through the other path.

Conflicts most often occur due to different ideas and opinions that team members must express, combine and share with each other as part of their creative process, in order to choose the best solutions (Nijstad et al., 2006). Exploring the link between task conflicts and performance in teams is still fraught with different results. A large amount of literature shows a negative relationship between the two terms (De Dreu \& Weingart, 2003). However, one study has shown a positive relationship when the following factors are in place, such as a positive atmosphere between team members (Jehn \& Mannix, 2001), conflict resolution strategies (Behfar et al., 2008) and trust (Simons \& Peterson, 2000). Recent empirical research supports the claim that conflict of tasks will aid some types of creative performance. Also, this research found that conflict of tasks has a positive effect, relationship conflict has a negative effect, and relationship asymmetry has a positive effect on creative performance. The results showed that relationship conflict and relationship conflict asymmetry affect creativity by encouraging divergent thinking to generate novelty, while task conflict, functional diversity and team size, affect creativity by stimulating convergent thinking to generate usefulness (Yong et al., 2014).

However, the effect sizes in the current study are small and further studies are needed to explore this finding. 


\section{Conclusions}

"Who speaks enters into a system of relationships that presuppose his presence and at the same time make him open and vulnerable" (Merleau-Ponty, 1973, p. 17).

The purpose of this research was to examine the use of silence in communication within the theory of spiral of silence. In particular, we investigated the tension, which relates to a discomfort in communication (Stohl \& Cheney, 2001, p. 353), misunderstandings (Foster-Fishman et al., 2001), or "tension when they face something that is frightening, astonishing, and perhaps even truly awesome" (Zimmermann \& Morgan, 2016, p. 403). "The need for members of social groups to feel satisfied and to freely engage in a deeper interaction, are met when they are feeling safe" (V. Baltezarevic \& R. Baltezarevic, 2016a, p. 251).

Silence as a nonverbal communication tool is often applied not only as shown in a spiral of silence theory that people are silent when confronted with the fear of social isolation, but also in other circumstances when communicators face with "others voice and its potential danger" (Gurevitch, 2001, p. 93), or with the dilemma "to be open and expressive, on one hand, and to be closed and private on the other" (Wood, 1997, p. 208).

The first hypothesis is confirmed as the results of the research have shown that there is a connection between the attitudes of the respondents that people with the opinions opposite of the group will keep quiet because they are afraid of social isolation, which leads to the conclusion that silence or "self-censoring" (Matthes et al., 2010) is used when people fear of being ostracized (Noelle-Neumann, 1974).

The second hypothesis is also confirmed because the results of the study showed that there is a connection between the respondents' attitudes with the claim that when a communicator fills a tension (Kramer, 2004, p. 330), silence is a modus for escaping from a communication process to avoid conflict, tension and uncomfortable situations.

The results showed, creativity is associated with keeping silent because of having opposite opinions and reducing the tension. Both associations show strong relationship. Using silence while having opposing views increases creativity by $87 \%$ and using silence to reduce the tension increases creativity by $59 \%$.

Finally, it is necessary to look at the crisis situation caused by the COVID-19 pandemic, which faced humanity with tension and conflicts, primarily as a result of dehumanization, due to recommended measures of social distance, but also subjective uneasiness of people, caused by economic insecurity and caring for the health of family members and themselves. In times of crisis, in which the COVID-19 pandemic disrupted the functioning of humanity, creativity and the ability to adapt to the new situation, in order to find a solution as quickly as possible (to continue doing business or education), are considered key roles of survival.

\section{Limitations and future research}

The limitation of this study is primarily in relation to the number of respondents. The authors' recommendation for future research also relates to the need to conduct further research in which the concept of tension in communication and research would be dealt with for the individual variables covered by this term. It will be particularly interesting to look 
at all the concepts explored in this research paper in the light of the COVID-19 pandemic. Restricted, turbulent and mainly digital reality represent an interesting avenue for studying the meaning of silence in communication with reference to creativity and innovation. The digital environment can help discover the creative potential of individuals, but also to give meaning to remote teamwork (Buisine \& Guegan, 2019). We would expect that results provided in the current study may differ in digital context.

\section{References}

Amabile, T. M. (1997). Motivating creativity in organizations: On doing what you love and loving what you do. California Management Review, 40(1), 39-58. https://doi.org/10.2307/41165921

Anderson, H. (1979). On nonresponse bias and response probabilities. Scandinavian Journal of Statistics, 6(3), 107-112.

Baker, S. J. (1955). The theory of silences. The Journal of General Psychology, 53(1), 145-167. https://doi.org/10.1080/00221309.1955.9710142

Baltezarevic, V., \& Baltezarevic, R. (2016a). How a communicator's emotional intelligence can improve the process of knowledge sharing. In M. Radovic-Markovic, I. Silver Kyaruzi, \& Z. Nikitovic (Eds.), Entrepreneurship: Types, current trends and future perspectives (pp. 248-260). Graphics, Inc.

Baltezarevic, V., \& Baltezarevic, R. (2016b, 19-20 May). The internet and virtual "Reality". In Proceedings of International Conference Technology + Society Future (pp. 193-200). Podgorica, Montenegro. Montenegrin Academy of Sciences and Arts.

Behfar, K. J., Peterson, R. S., Mannix, E. A., \& Trochim, W. M. K. (2008). The critical role of conflict resolution in teams: A close look at the links between conflict type, conflict management strategies, and team outcomes. Journal of Applied Psychology, 93(1), 170-188. https://doi.org/10.1037/0021-9010.93.1.170

Braithwaite, Ch. A. (2009). Communicative silence: A cross-cultural study of basso's hypothesis. In D. Carbaugh (Ed.), Communication textbook series. Cultural communication and intercultural contact (pp. 321-328). J. Bryant (Ed.). Psychology Press.

Broner-Bauer, K. (1998). Aarno Ruusuvuori and the continuity of Finnish modernism. In M. Quantrill \& B. Webb (Eds.), The culture of silence: Architecture's fifth dimension (pp. 195-211). Texas A\&M University Press.

Buisine, S., \& Guegan, J. (2019). Creativity in virtual teams: Bridging the gap between professional wisdom and scientific insights. Creativity Studies, 12(2), 198-210. https://doi.org/10.3846/cs.2019.576

Byron, K., Khazanchi, Sh., \& Nazarian, D. (2010). The relationship between stressors and creativity: A meta-analysis examining competing theoretical models. Journal of Applied Psychology, 95(1), 201-212. https://doi.org/10.1037/a0017868

Carbaugh, D. (2010). Lea's communication series. Cultures in conversation. J. Bryant \& D. Zillmann (General Eds.). Routledge.

Cook, P. (2002). Best practice creativity. Gower Publishing Limited.

Courtenay, Ch. (1916). The empire of silence. Sturgis \& Walton.

Cutting, J. (2008). Pragmatics and discourse: A resource book for students. Routledge.

Dewett, T. (2004). Employee creativity and the role of risk. European Journal of Innovation Management, 7(4), 257-266. https://doi.org/10.1108/14601060410565010

Dreu, De C. K. W., \& Weingart, L. R. (2003). Task versus relationship conflict, team performance, and team member satisfaction: A meta-analysis. Journal of Applied Psychology, 88(4), 741-749.

https://doi.org/10.1037/0021-9010.88.4.741 
Duff, P. A. (2002). The discursive co-construction of knowledge, identity, and difference: An ethnography of communication in the high school mainstream. Applied Linguistics, 23(3), 289-322. https://doi.org/10.1093/applin/23.3.289

Foster-Fishman, P. G., Salem, D. A., Allen, N. A., \& Fahrbach, K. (2001). Facilitating interorganizational collaboration: The contributions of interorganizational alliances. American Journal of Community Psychology, 29(6), 875-905. https://doi.org/10.1023/A:1012915631956

Glynn, C. J., Hayes, A. F., \& Shanahan, J. (1997). Perceived support for one's opinions and willingness to speak out: A meta-analysis of survey studies on the "Spiral of Silence". Public Opinion Quarterly, 61(3), 452-463. https://doi.org/10.1086/297808

Gould, T. (2008). Topic development, affiliative mimesis and L1 use in a novice-novice L2 English conversation. Sophia Junior College Faculty Journal, 28, 9-26.

Guilford, J. P. (1950). Creativity. American Psychologist, 5(9), 444-454. https://doi.org/10.1037/h0063487

Guo, L., Decoster, S., Babalola, M. T., De Schutter, De L., Garba, O. A., \& Riisla, K. (2018). Authoritarian leadership and employee creativity: The moderating role of psychological capital and the mediating role of fear and defensive silence. Journal of Business Research, 92, 219-230.

https://doi.org/10.1016/j.jbusres.2018.07.034

Gurevitch, Z. (2001). Dialectical dialogue: The struggle for speech, repressive silence, and the shift to multiplicity. The British Journal of Sociology, 52(1), 87-104. https://doi.org/10.1080/00071310020023046

Hayes, A. F. (2007). Exploring the forms of self-censorship: On the spiral of silence and the use of opinion expression avoidance strategies. Journal of Communication, 57(4), 785-802. https://doi.org/10.1111/j.1460-2466.2007.00368.x

Jaworski, A. (1993). Language and language behaviors: Vol. 1. The power of silence: Social and pragmatic perspectives. H. Giles (Series Ed.). SAGE Publications, Inc. https://doi.org/10.4135/9781483325460

Jeffres, L. W., Neuendorf, K. A., \& Atkin, D. (1999). Spirals of silence: Expressing opinions when the climate of opinion is unambiguous. Political Communication, 16(2), 115-131. https://doi.org/10.1080/105846099198686

Jehn, K. A., \& Mannix, E. A. (2001). The dynamic nature of conflict: A longitudinal study of intragroup conflict and group performance. Academy of Management Journal, 44(2), 238-251. https://doi.org/10.5465/3069453

Kane, L. (1984). The language of silence: On the unspoken and the unspeakable in modern drama. Fairleigh Dickinson University Press/Associated University Presses, Inc.

Kim, H. S. (2002). We talk, therefore we think? A cultural analysis of the effect of talking on thinking. Journal of Personality and Social Psychology, 83(4), 828-842. https://doi.org/10.1037/0022-3514.83.4.828

Kramer, M. W. (2004). Toward a communication theory of group dialectics: An ethnographic study of a community theatre group. Communication Monographs, 71(3), 311-332. https://doi.org/10.1080/0363452042000288292

LeClaire, A. D. (2010). Listening below the noise: The transformative power of silence. HarperCollins Publishers.

Levelt, W. J. M. (1993). ACL-MIT press series in natural-language processing. Speaking: From intention to articulation. A. Joshi (Ed.). A Bradford Book/The MIT Press. https://doi.org/10.7551/mitpress/6393.001.0001

Liu, X., \& Fahmy, Sh. (2011). Exploring the spiral of silence in the virtual world: lndividuals' willingness to express personal opinions in online versus offline settings. Journal of Media and Communication Studies, 3(2), 45-57.

Matthes, J., Rios Morrison, K., \& Schemer, Ch. (2010). A spiral of silence for some: Attitude certainty and the expression of political minority opinions. Communication Research, 37(6), 774-800.

https://doi.org/10.1177/0093650210362685 
Mayer, C.-H., \& Maree, D. (2018). A writer's creativity across the life span: Paulo Coelho in psychobiographical perspective. Journal of Genius and Eminence, 3(1), 85-98.

https://doi.org/10.18536/jge.2018.04.3.1.09

Mazur, P. S., \& Duchlinski, P. (2020). Credibility and creativity in network society. Creativity Studies, 13(1), 53-63. https://doi.org/10.3846/cs.2020.6585

Merleau-Ponty, M. (1973). Northwestern university studies in phenomenology and existential philosophy. The prose of the world. Northwestern University Press.

Montgomery, B. M. (1993). Relationship maintenance versus relationship change: A dialectical dilemma. Journal of Social and Personal Relationships, 10(2), 205-223. https://doi.org/10.1177/026540759301000203

Montgomery, B. M., \& Baxter, L. A. (Eds.). (2008). Dialectical approaches to studying personal relationships. Psychology Press.

Moore, Th. (2008). A life at work: The joy of discovering what you were born to do. Broadway Books.

Moy, P., Domke, D., \& Stamm, K. (2001). The spiral of silence and public opinion on affirmative action. Journalism and Mass Communication Quarterly, 78(1), 7-25. https://doi.org/10.1177/107769900107800102

Mullen, B., Johnson, C., \& Salas, E. (1991). Productivity loss in brainstorming groups: A meta-analytic integration. Basic and Applied Social Psychology, 12(1), 3-23. https://doi.org/10.1207/s15324834basp1201_1

Nakane, I. (2007). Pragmatics and beyond new series. Silence in intercultural communication: Perceptions and performance. John Benjamins Publishing Company. https://doi.org/10.1075/pbns.166

Nijstad, B. A., Rietzschel, E. F., \& Stroebe, W. (2006). Four principles of group creativity. In L. Thompson \& H. S. Choi (Eds.), Lea's organization and management series. Creativity and innovation in organizational teams (pp. 161-179). Lawrence Erlbaum Associates, Publishers.

Noelle-Neumann, E. (1974). The spiral of silence: A theory of public opinion. Journal of Communication, 24(2), 43-51. https://doi.org/10.1111/j.1460-2466.1974.tb00367.x

Padilla Cruz, M. (2008). Phatic utterances as face-threatening/saving acts or politeness strategies: A pragmatic reflection for their teaching in the L2 class. In R. Monroy \& A. Sánchez (Eds.), 25 years of applied linguistics in Spain: Milestones and challenges (pp. 799-804). Editum.

Picard, A. (1963). Classic reprint series. Man and language. Henry Regnery.

Prentice, C. M., \& Kramer, M. W. (2006). dialectical tensions in the classroom: Managing tensions through communication. Southern Communication Journal, 71(4), 339-361. https://doi.org/10.1080/10417940601000436

Republika Srbija: Republički zavod za statistiku. (2020). Procena stanovništva, po starosti i polu (početak, sredina $i$ kraj godine). https://data.stat.gov.rs/Home/Result/18010403?languageCode=sr-Latn

Richmond, V. P., \& McCroskey, J. C. (1999). Nonverbal behavior in interpersonal relations. Allyn \& Bacon.

Ritchie Key, M. (1975). Male/female language. Scarecrow Press.

Runco, M. A. (2017). Creative interpretations of educational contradictions. In R. A. Beghetto \& B. Sriraman (Eds.), Creativity theory and action in education: Vol. 1. Creative contradictions in education: Cross disciplinary paradoxes and perspectives (pp. 75-88). Springer International Publishing. https://doi.org/10.1007/978-3-319-21924-0_5

Runco, M. A., \& Okuda Sakamoto, Sh. (2002). Experimental studies of creativity. In R. J. Sternberg (Ed.), Handbook of creativity (pp. 62-92). Cambridge University Press. https://doi.org/10.1017/CBO9780511807916.006

Sarton, M. (1999). From May Sarton's well: Writings of May Sarton. E. Royce Schade (Ed.). Goodale Hill Press.

Saunders, G. R. (1985). Silence and noise as emotion management styles: An Italian case. In D. Tannen \& M. Saville-Troike, (Eds.), Perspectives on silence (pp. 165-184). Ablex Publishing Corporation. 
Scheufle, D. A., \& Moy, P. (2000). Twenty-five years of the spiral of silence: A conceptual review and empirical outlook. International Journal of Public Opinion Research, 12(1), 3-28. https://doi.org/10.1093/ijpor/12.1.3

Shafik, A. (2011). Global peace lovers. Author House.

Siegel, D. J. (2007). The mindful brain: Reflection and attunement in the cultivation of well-being. W. W. Norton \& Company.

Silvas, A. M. (2005). Oxford early Christian studies. The Asketikon of St Basil the Great. Oxford University Press.

Simons, T. L., \& Peterson, R. S. (2000). Task conflict and relationship conflict in top management teams: The pivotal role of intragroup trust. Journal of Applied Psychology, 85(1), 102-111. https://doi.org/10.1037/0021-9010.85.1.102

Simpson, Ch. (1996). Elisabeth Noelle-Neumann's "Spiral of silence" and the historical context of communication theory. Journal of Communication, 46(3), 149-173.

https://doi.org/10.1111/j.1460-2466.1996.tb01494.x

Sloan Wilson, D., \& Wilson, E. O. (2007). Evolution: Survival of the selfless. New Scientist, 196(2628), 42-46. https://doi.org/10.1016/S0262-4079(07)62792-4

Starks, G. L. (2006). Managing conflict in public organizations. Public Manager, 35(4), 55-60.

Stohl, C., \& Cheney, G. (2001). Participatory processes/paradoxical practices: Communication and the dilemmas of organizational democracy. Management Communication Quarterly, 14(3), 349-407. https://doi.org/10.1177/0893318901143001

Tannen, D. (1990). Silence as conflict management in fiction and drama: Pinter's Betrayal and a short story, "Great Wits". In A. D. Grimshaw (Ed.), Conflict talk: Sociolinguistics investigations of arguments in conversations (pp. 260-279). Cambridge University Press.

Tannen, D., \& Saville-Troike, M. (Eds.). (1985). Perspectives on silence. Ablex Publishing Corporation.

Tatar, S. (2005). Why keep silent? The classroom participation experiences of non-native-English-speaking students. Language and Intercultural Communication, 5(3-4), 284-293. https://doi.org/10.1080/14708470508668902

Taylor, D. G. (1982). Pluralistic ignorance and the spiral of silence: A formal analysis. Public Opinion Quarterly, 46(3), 311-335. https://doi.org/10.1086/268729

Ulger, K. (2020). A review of the criteria of the prediction of students' creative skills in the visual arts education. Creativity Studies, 13(2), 510-531. https://doi.org/10.3846/cs.2020.11860

Umeh, J. T. (2010). The use of strategic silence in community relations. International Journal of Communication, 4(2), 11-23.

Wetzstein, A., \& Hacker, W. (2004). Reflective verbalization improves solutions - the effects of question-based reflection in design problem solving. Applied Cognitive Psychology, 18(2), 145-156. https://doi.org/10.1002/acp.949

Wilson, D. (2005). New perspective in applied communication. Stirling-Horden Publishers (Nig) Ltd.

Woerkum, van C. M. J., Aarts, M. N. C., \& Grip, de K. (2007). Creativity, planning and organizational change. Journal of Organizational Change Management, 20(6), 847-865. https://doi.org/10.1108/09534810710831055

Wood, J. T. (1997). Communication theories in action: An introduction. Wadsworth Publishing Company.

Yong, K., Sauer, S. J., \& Mannix, E. A. (2014). Conflict and creativity in interdisciplinary teams. Small Group Research, 45(3), 266-289. https://doi.org/10.1177/1046496414530789

Zimmermann, A. C., \& Morgan, W. J. (2016). A time for silence? Its possibilities for dialogue and for reflective learning. Studies in Philosophy and Education, 35, 399-413.

https://doi.org/10.1007/s11217-015-9485-0

Zuo, Y. (2002). The golden silence: A pragmatic study on silence in Dyadic English conversation. Lincom Europa. 